\title{
Posicionamentos teórico-metodológicos sobre identidade semântica e categorização de unidades linguísticas: de Émile Benveniste a Antoine Culioli
}

\author{
Márcia Romero ${ }^{1}$ \\ Escola de Filosofia, Letras e Ciências Humanas/PPG em Educação e Saúde na Infância e na Adolescência, \\ Universidade Federal de São Paulo, Guarulhos, SP, Brasil
}

Resumo: $O$ presente trabalho toma por objeto de análise a metodologia levada a efeito por Benveniste em artigos nos quais se abordam unidades linguísticas de natureza morfolexical, a saber Le système sublogique des prépositions en latin (BENVENISTE, 1966) e Problèmes sémantiques de la reconstruction (BENVENISTE, 1966). Nosso propósito é o de verificar de que forma a problematização dos dados apresentada por Benveniste traz consequências para a compreensão da identidade semântica e categorização da unidade linguística, em seus artigos e naqueles de Antoine Culioli, autor igualmente inscrito no campo da Linguística da Enunciação. Os resultados mostram como Benveniste, por meio da referência a uma significação geral, igualmente apreendida em termos de definição constante, esquema sublógico, esquema subjacente, ao dialogar com o conceito de invariância próprio ao quadro referencial da Teoria das Operações Predicativas e Enunciativas, confere à língua seu estatuto enunciativo.

Palavras-chave: Linguística da enunciação; Identidade semântica; Categorização; Benveniste; Culioli.

Title: Theoretical and methodological positions on semantic identity and categorization of linguistic units: from Émile Benveniste to Antoine Culioli

Abstract: Our object of analysis in this paper is the methodology carried out by Benveniste in articles where linguistic units of morpholexical nature are studied, namely, The sublogical system of prepositions in Latin (BENVENISTE, 1966) and Semantic Problems in Reconstruction (BENVENISTE, 1966). We aim at analyzing how the examination of data presented by Benveniste brings consequences to the understanding of semantic identity and categorization of the linguistic unit in his articles and in those of Antoine Culioli, a linguist that also belongs to the field of enunciative linguistics. The results show how Benveniste assigns to language its enunciative status by establishing a dialogue with the concept of invariance (from the framework of Culioli's Theory of the Predicative and Enunciative Operations) and by referring to a general signification, equally understood as constant definition, sublogical schema, and underlying schema.

Keywords: Enunciative linguistics; Semantic identity; Categorization; Benveniste; Culioli.

\footnotetext{
${ }^{1}$ Doutor (Universidade de São Paulo), Universidade Federal de São Paulo. http://orcid.org/0000-0001-5204111X. E-mail: marcia.romero@unifesp.br.
} 


\section{Apresentação}

Tomando por objeto de análise a própria metodologia posta em prática por Émile Benveniste em dois artigos nos quais se abordam unidades linguísticas de natureza morfolexical, a saber Le système sublogique des prépositions en latin (BENVENISTE, 1966) e Problèmes sémantiques de la reconstruction (BENVENISTE, 1966) ${ }^{2}$, nosso propósito é o de verificar as contribuições trazidas pelo autor para a definição de conceitos relacionados à natureza da identidade semântica e à categorização de unidades linguísticas, em seus estudos e naqueles posteriormente desenvolvidos por Antoine Culioli, ambos inscritos no campo da Linguística da Enunciação.

Para tanto, procedemos por etapas: na primeira, analisamos excertos extraídos dos artigos de modo a compreender as conclusões às quais chega o autor no que se refere à semântica das unidades; na segunda, verificamos quais as consequências do trabalho metodológico efetuado para o posicionamento teórico sobre identidade semântica da unidade linguística e categorização linguística; por fim, na terceira etapa, esta conclusiva, mostramos, sucintamente, de que modo Antoine Culioli, em sua Teoria das Operações Predicativas e Enunciativas (CULIOLI, 1990, 1999a, 1999b, 2018) encontra, em suas reflexões direcionadas ao tema em questão, Émile Benveniste.

\section{Do trabalho metodológico direcionado à unidade morfolexical}

Selecionamos, para abrir essa seção, excertos extraídos do artigo Le système sublogique des prépositions en latin (BENVENISTE, 1966), publicado em 1949. Nesse trabalho, Benveniste tem por objetivo apresentar as particularidades específicas à semântica de prae que sustentam seus diferentes empregos, inclusive os categorizados como prae causal e prae comparativo, comumente diferenciados pela própria categorização estabelecida.

$\mathrm{Na}$ abertura do artigo, é dito que:

É preciso insistir neste ponto: cada preposição de um determinado idioma desenha, em seus diversos empregos, uma certa figura na qual se coordenam seus sentidos e suas funções e que precisamos reconstituir se quisermos dar uma definição coerente do conjunto de suas particularidades semânticas e gramaticais. (...) [Resume-se aqui uma] pesquisa independente que visa, antes, a mostrar que uma tal descrição permite resolver os problemas concretos que o emprego de uma preposição traz. (BENVENISTE, 1966, p. 132, grifos nossos).

Benveniste afirma, na continuidade do trabalho, distinguir pro de prae, às quais os latinistas conferem um sentido semelhante. Para tanto, discerne em prae, segundo palavras suas, os caracteres seguintes:

\footnotetext{
${ }^{2}$ As citações foram traduzidas por nós do texto original.
} 
10 indica não a posição "diante", mas "na frente" de um objeto; este objeto é sempre concebido como contínuo, de modo que prae especifica a porção anterior do objeto com relação àquela que é posterior; a relação estabelecida por prae implica que o sujeito deve constituir ou ocupar a parte posterior; daí parte o movimento prae, em direção ao que está na frente, na extremidade, antecipado ou em excesso, mas sempre sem solução de continuidade da parte detrás, posição "normal", para a frente, posição "extrema". (BENVENISTE, 1966, p. 133, grifos do autor)

Esses dois excertos já nos permitem fazer algumas considerações sobre o posicionamento teórico-metodológico do autor: do ponto de vista teórico, Benveniste, ao afirmar que cada preposição de um determinado idioma desenha uma certa figura a ser reconstituída, aponta, de saída, para duas questões importantes: o sentido adquirido por uma dada unidade linguística em seu emprego é fruto de uma figura não qualquer, que cabe reconstituir; esta figura, na especificação dos caracteres de prae, toma a forma de uma relação na qual se descreve o que faz prae ao se enunciar. Nota-se, assim, que a natureza da semântica de prae é, não da ordem de um sentido ou conteúdo, mas de ordem relacional, em que variáveis são mobilizadas, ainda que o termo variável não seja utilizado pelo autor: porção anterior e posterior do objeto, localização do sujeito na parte posterior. A partir delas, é que se diz que o movimento parte do posterior para o que está na frente, sem solução de continuidade da parte detrás. Do ponto de vista metodológico, isso implica verificar a maneira pela qual essas variáveis se fazem presentes em um conjunto de empregos distintos de prae.

É a isso que vai se dedicar Benveniste no decorrer do trabalho, ao analisar um conjunto de empregos em que prae se faz presente: pôr em teste a definição trazida. Assim, em i prae, iam ego te sequar (PI., Cist., 773, citado por BENVENISTE, 1966, p. 133), e que traduzimos por Vai na frente, já te seguirei, na análise feita por nós e que toma por fundamento os caracteres estabelecidos, a presença de prae mostra que: 1‥ considera-se a posição do locutor para definir a posição do interlocutor como o que se encontra à sua frente; 2o. o movimento do locutor o toma por ponto de referência, de modo que o deslocamento do locutor segue o deslocamento do interlocutor. Embora a análise seja de nossa responsabilidade, acreditamos que é por ter desenvolvido um raciocínio semelhante que Benveniste afirma, ao final, que: "Uma vez enunciado prae, o objeto é figurado como contínuo, e o resto deve "seguir"; sendo contínuo, não pode não seguir" (BENVENISTE, 1966, p. 133). Importa observar, ainda, nessa colocação do autor, como o fato de se empregar prae resulta em uma mobilização não qualquer do contexto verbal: sequar responde ao que é solicitado por prae.

Após uma série de exemplos, nos quais cabe ao leitor, como fizemos, reconstituir o pensamento analítico de Benveniste, o autor entra na questão que lhe interessa mais diretamente, que é a de explicar os empregos causal e comparativo da preposição:

Até este ponto, foi relativamente fácil verificar (...) o sentido geral conferido a prae. A verdadeira dificuldade começa quando se quer explicar os empregos causal e comparativo da preposição. (...) Sabemos que prae está apto para indicar a causa: (...) prae laetitia lacrimae prosiliunt mihi (Plauto, citado por BENVENISTE, 1966, p. 136) (de alegria, minhas lágrimas brotam) (BENVENISTE, 1966, p. 135-136, grifos nossos). 
Pode também marcar uma comparação: (...) Gallis prae magnitudine corporum suorum brevistas nostra contemptui est (César, citado por BENVENISTE, 1966, p. 138) (aos olhos dos Gauleses, nossa pequena estatura ao lado da sua alta estatura é um objeto de desprezo). (BENVENISTE, 1966, p. 136 e p. 138, grifos nossos)

O autor afirma que as interpretações fornecidas até então para esses empregos não permitem compreender o que se encontra em sua gênese, o que o leva, de um lado, a afastar as "pseudos-soluções" (BENVENISTE, 1966, p. 137), de outro, a observar que "a solução deve decorrer das condições postas para a significação geral da preposição. O prae causal e o prae comparativo devem se explicar juntos pelo mesmo esquema sublógico que está na base dos empregos comuns de prae" (BENVENISTE, 1966, p. 137, grifos nossos).

Benveniste inicia a sua análise mostrando que o emprego de prae causal obedece a condições estritas:

1‥ prae causal tem sempre por complemento um termo de sentimento; $2 \circ$. esse termo de sentimento afeta sempre o sujeito do verbo, de modo que a condição enunciada por prae está em relação interna e "subjetiva" com o processo verbal, sendo sempre o sujeito do processo verbal o possuidor do sentimento; Quando prae marca uma causa, essa causa não está objetivamente colocada fora do sujeito e relacionada a um fator externo, mas reside em um algum sentimento próprio ao sujeito e, mais exatamente, prende-se a um certo grau desse sentimento. Com efeito, todos os exemplos fazem aparecer o grau extremo do sentimento vivido pelo sujeito. Aqui está a explicação de prae, que significa literalmente "na extremidade" da afeição entrevista, portanto, "no extremo": "no auge de minha alegria, minhas lágrimas brotam". (BENVENISTE, 1966, p. 137, grifos do autor, exceto para condição enunciada, cujos grifos são nossos)

Essas colocações nos permitem, uma vez mais, reler o exemplo trazido sob a ótica dos caracteres de prae anteriormente apresentados: minhas lágrimas seria o termo que recupera o sentimento que as motiva e que as antecede (que lhes é anterior), i.e. a alegria, sentimento próprio ao sujeito a ser tomado como ponto de referência e em seu mais alto grau em relação a um contínuo dado por uma gradação (no auge).

Torna-se assim, a nosso ver, mais facilmente compreendida a explicação de Benveniste sobre o fato de que se fala equivocadamente de um sentido "causal":

Indicando o movimento em direção à parte anterior e mais avançada de um contínuo, prae deixa de certo modo o resto do objeto em situação de inferioridade. (...) Prae não faz intervir uma causa objetiva; ele marca apenas um ponto extremo, um excesso, que tem por consequência uma certa disposição, geralmente negativa ${ }^{3}$ do sujeito. (BENVENISTE, 1966, p. 138)

No que se refere ao prae comparativo, tem-se uma vez mais a noção de extremo: "o complemento de prae designa aquele dos dois termos que é superior ao outro" (Riemann, citado por BENVENISTE, 1966, p. 138). Com relação ao exemplo já mencionado, a saber, Gallis prae magnitudine corporum suorum brevistas nostra contemptui est (aos olhos dos Gauleses,

\footnotetext{
${ }^{3} \mathrm{O}$ "geralmente negativo" aparece em exemplos como non me commovere possum prae formidine (no auge de meu medo, não posso me mexer), em que a disposição não posso me mexer é valorada negativamente.
} 
nossa pequena estatura ao lado da sua alta estatura é um objeto de desprezo), o autor afirma que "é aqui também da noção de "extremo" que resulta a função comparativa de prae, pois prae magnitudine significa "no extremo de seu tamanho = tão alta é a sua altura (que nós lhes parecemos pequenos)" (BENVENISTE, 1966, p. 138).

Interessante notar, aliás, que a noção de medida se vincula a um contínuo: o extremo se dá em relação a uma seriação de medidas. Nesse caso, "a altura (em seu extremo)" é o ponto de referência primeiro em relação a outras medidas de altura, que consequentemente, o seguem.

Como dissemos, para entender as considerações feitas por Benveniste, somos obrigados a reconstituir um raciocínio que não se encontra necessariamente explicitado em suas análises. Embora não tenhamos como saber se conseguimos recuperá-lo de modo preciso, isso não interfere na conclusão à qual chegamos, ou seja, a de que se vê como o objetivo inicialmente exposto por Benveniste e que envolve uma certa figura a ser reconstituída, é alcançado nas diferentes análises. Daí, em fechamento, ser dito que:

Todos os empregos de prae cabem em uma definição constante. Quisemos mostrar, com um exemplo, que, no estudo das preposições, quaisquer que sejam o idioma e a época considerados, uma nova técnica de descrição é necessária e torna-se possível, para restituir a estrutura de cada uma das preposições e integrar essas estruturas num sistema geral. A tarefa acarreta a obrigação de reinterpretar todos os dados adquiridos e refundir as categorias estabelecidas. (BENVENISTE, 1966, p. 139, grifos nossos)

Vale notar ainda que, no artigo Pour une sémantique de la préposition allemande vor (BENVENISTE, 1974), publicado em 1972, no qual não vamos nos deter nesse trabalho por uma questão de prioridades, Benveniste mantém seu objetivo de reconstituir, por meio do exame de diferentes empregos da preposição vor, o que seria capaz de explicá-los em sua diversidade.

Nesse artigo, no entanto, ao invés de falar em uma certa figura na qual se coordenam seus sentidos e suas funções, definição constante ou esquema sublógico, como se vê no artigo sobre prae por nós analisado, Benveniste fala em esquema subjacente e, mais, em efeitos de sentido dele resultante, como se vê no excerto abaixo, em que o autor se refere a duas construções nas quais vor se faz presente:

A língua não poderia produzir construções tão parecidas se não houvesse entre elas uma similitude profunda devida a um mesmo esquema subjacente. Cabe ao linguista descobrir essas relações profundas sob a diversidade superficial dos empregos, se ele quiser compreender os efeitos de sentido que delas resultam (BENVENISTE, 1966, p. 139, grifos nossos)

Seu objetivo, portanto, se mantém por mais de duas décadas, dado que o artigo sobre prae é de 1949 e este, de 1972. E responder a esse objetivo sustenta igualmente outros artigos que têm por foco, não o campo da variação semântica no âmbito de uma mesma língua, caso justamente dos artigos voltados para prae e seus diferentes empregos em latim, ou para vor e suas diferentes construções em alemão, mas o campo da variação relacionada a diferentes 
línguas.

Com efeito, é o que se observa no artigo Problèmes sémantiques de la reconstruction (1966), que data de 1954. Neste artigo, Benveniste chama a atenção, de saída, para o problema que envolve a significação, um problema recorrente, seja "no interior de uma mesma língua ou nas diferentes etapas de uma reconstrução comparativa, [a saber: o problema de] determinar se e como dois morfemas formalmente idênticos ou comparáveis podem ser identificados por meio de seu sentido" (BENVENISTE, 1966, p. 289). Daí, justamente, que:

O único princípio empregado nas considerações que seguem, tomando-o como admitido, é que o "sentido" de uma forma linguística se define pela totalidade de seus empregos, por sua distribuição e pelos tipos de vínculos deles resultam. $\mathrm{Na}$ presença de morfemas idênticos com dois sentidos diferentes, a resposta [para a existência de uma unidade] só pode ser fornecida por um estudo atento do conjunto dos contextos em que a forma é suscetível de aparecer. (BENVENISTE, 1966, p. 289-290)

São inúmeros os exemplos dados por Benveniste neste texto tão denso quanto belo. Selecionamos o que envolve a discussão sobre o substantivo "caminho": "sânscr. pánthāt, (...), arm. hun, ant. esl. pqtĭ, (...), gr. póntos, lat. pons (BENVENISTE, 1966, p. 296-298)”, discussão aberta com a seguinte consideração do autor:

No quadro de uma comparação em grande escala, em que várias línguas são consideradas, constata-se frequentemente que formas evidentemente aparentadas se distinguem cada uma por uma variedade particular de sentido. Embora a unidade semântica da família seja inegável, ela não parece poder se definir exatamente. Tem-se a impressão de que o "sentido primeiro", conservado exatamente por uma língua, foi desviado por razões particulares em cada uma das outras, produzindo assim uma imagem compósita da situação semântica. (BENVENISTE, 1966, p. 296)

Ora, aparentemente, é o que poderia se verificar nas formas acima mencionadas e outras, já que, "no indo-irânico, no eslavo e no báltico, trata-se do "caminho". O gr. póntos, no entanto, significa "mar"; o lat. pons designa a "ponte" e o arm. hun, o "vau"" (BENVENISTE, 1966, p. 297).

As explicações dadas por Benveniste a respeito de como se concebe a variação de sentido são, contudo, bastante esclarecedoras e isso por mostrarem o quanto as representações no que concerne à significação tendem a se fundamentar em um "sentido primeiro" (que ele mesmo utiliza entre aspas) que se quer, a todo custo, tomar como fundamento:

Como esses sentidos não se equivalem e que, na distribuição dialetal, é especialmente em grego e em latim que a divergência se manifesta, tende-se a pensar que esse desacordo se deve às razões de estilo ou de cultura. Em grego, é uma figuração poética que teria assimilado "mar" a um "caminho". Em latim, a transferência de "caminho" a "ponte" resultaria da civilização dos terramares... Essas hipóteses têm por fundamento uma outra hipótese, não reconhecida como tal, não formulada e inconsciente: o sentido primeiro seria o de "caminho", quer por ser atestado em um dialeto antigo como o indo-irânico, quer por causa do acordo entre 
o indo-irânico, o eslavo e o báltico, ou em virtude de sua "simplicidade"; e os sentidos de "mar" ou "ponte" ou "vau" seriam desvios dele. (BENVENISTE, 1966, p. 297)

Para mostrar que esse modo de olhar para os dados não é pertinente, Benveniste retoma o sânscr. pánthāt a partir da análise de empregos em textos védicos - os textos antigos mais abundantes, em suas palavras - que permitem, segundo ele, aceder a uma noção mais exata deste termo. Assim, o autor observa que há muitos outros substantivos para "caminho", distintos do especificado pelo emprego de pánthāt, que "não é simplesmente o caminho como espaço a percorrer de um ponto a outro" (BENVENISTE, 1966, p. 297):

Ele implica pena, incerteza e perigo, ele tem desvios imprevisíveis, pode variar com aquele que o percorre e, aliás, não é apenas terrestre, os pássaros têm o seu, os rios também. O pánthāt não está, portanto, traçado de antemão, nem é seguido regularmente. É, antes, uma "transposição" tentada através de uma região desconhecida e frequentemente hostil, (...) uma travessia de obstáculos naturais, ou a estrada que os pássaros inventam no espaço (...). O equivalente mais próximo é mais "transposição" do que "caminho" e é esse sentido que explica a diversidade das variantes atestadas. (BENVENISTE, 1966, p. 297-298)

Ora, interessante notar que, embora Benveniste fale que transposição seria o "sentido que explica a diversidade das variantes atestadas", o que se percebe é sobretudo uma descrição de transposição que poderia ser explicada igualmente por meio de variáveis, uma vez que, ao se voltar para os substantivos nas diferentes línguas, encontra-se, para transposição - relacionado à noção de transpor algo -, dois elementos considerados a priori distintos e que passam a ser vistos como contínuos. Daí, por exemplo, no excerto abaixo, a explicação fazer referência à "passagem entre dois continentes" ou à "ponte" como o que permite transpor o que o curso d'água ou a depressão separam:

Em grego, a "transposição" é aquela de um braço de mar, depois mais amplamente de uma extensão marítima servindo de "passagem" entre dois continentes; (...) em latim, pons designará o transpor de um curso d'água ou de uma depressão, portanto, uma "ponte". (...) Ao menos, percebe-se que "caminho", "braço de mar", "vau", "ponte" são como as variantes de uma significação que eles deixam reconstruir, e que o problema não diz respeito ao aspecto semântico do termo nesta ou naquela língua, mas se coloca para cada um deles e para a família inteira da qual são os membros. (BENVENISTE, 1966, p. 298)

Por fim, na conclusão, Benveniste diz ser pelas relações que se define uma estrutura semântica, relações às quais não temos como chegar se não observamos detalhadamente os empregos da unidade analisada:

Em todos os casos discutidos, está implicado um problema de relação, e é pelas relações que se define uma estrutura semântica. (...) As questões precedentes giram em torno de uma mesma questão, que é a identificação dos traços distintivos por oposição às variantes: como definir a distribuição e as capacidades combinatórias de um "sentido"; como um sentido tido por diferente de um outro pode representar apenas um de suas variantes (...), todos problemas que seriam transpostos imediatamente em termos de fonêmica. Mas as noções semânticas, muito mais complexas, mais difíceis de objetivar e sobretudo de formalizar (...) pedem em 
primeiro lugar uma descrição dos empregos, únicos que permitem definir um sentido. E essa descrição exige que nos libertemos das falsas evidências, das referências às categorias semânticas "universais", das confusões entre os dados a estudar e aquelas da língua do descritor. (BENVENISTE, 1966, p. 307, grifos nossos)

Importa destacar e guardar que, se se trata de identificar "traços distintivos", esses traços relacionam-se à análise dos diferentes empregos, aos caracteres tais como mencionados no artigo direcionado ao estudo de prae. Isso os diferencia, de saída, de traços de conteúdo dados a priori e tidos como "categorias semânticas universais". Aliás, como bem observa o autor nesse último excerto, não se trata de problematizar fazendo uma aplicação em "termos de fonêmica": as noções semânticas são, evidentemente, muito mais complexas.

\title{
Consequências para o posicionamento teórico sobre identidade semântica e categorização da unidade linguística
}

Nessa seção, apoiados em um conjunto de excertos extraídos dos artigos Nature $d u$ signe linguistique, La classification des langues e Les niveaux de l'analyse linguistique, que constam de Benveniste (1966), e, ainda, de Sémiologie de la langue e La forme et le sens dans le langage, que constam de Benveniste (1974), procuramos mostrar de que forma a problematização dos dados apresentada na seção anterior traz consequências para a compreensão de conceitos que tocam a questão da identidade semântica e categorização da unidade linguística.

Iniciamos com a apresentação de excertos do artigo La classification des langues (BENVENISTE, 1966):

\begin{abstract}
O dado linguístico é um resultado, e é preciso procurar-Ihe a origem. Uma reflexão um pouco mais atenta ao modo pelo qual uma língua - pelo qual toda língua - se constrói ensina que cada língua tem para resolver um certo número de problemas, que se reduzem todos à questão central da "significação". As formas gramaticais traduzem, com um simbolismo que é a marca distintiva da linguagem, a resposta dada a esses problemas; estudando essas formas, a sua seleção, o seu agrupamento, a sua organização próprios, podemos induzir a natureza e a forma do problema intralinguístico a que respondem. Todo esse processo é inconsciente, difícil de ser atingido, mas essencial. (...) É preciso começar a ver além da forma material (...). Uma coisa é certa: posto que uma classificação integral significa um conhecimento integral, é por uma compreensão sempre mais profunda e uma definição sempre mais estrita dos signos linguísticos que progrediremos em direção a uma classificação racional. (BENVENISTE, 1966, p. 117-118)
\end{abstract}

Evidencia-se, nesses excertos, que, de um lado, há um problema intralinguístico relacionado à questão da significação e que formas, em seus agenciamentos próprios, respondem a esse problema; de outro, que o modo como se define o signo é o que permite progredir em relação à compreensão desse problema e à própria classificação entrevista - no caso, das línguas. Observemos que, de acordo com o autor, se não for esse o caminho tomado, ele "estará definitivamente fechado para toda investigação profunda sobre a natureza e as manifestações da linguagem" (BENVENISTE, 1966, p. 117). 
Do artigo Les niveaux de l'analyse linguistique (BENVENISTE, 1966), selecionamos os excertos abaixo, pois ambos mencionam o fato de o sentido da unidade linguística fora da frase não ser equivalente àquele que a unidade adquire na frase:

\begin{abstract}
Uma frase constitui um todo, que não se reduz à soma das suas partes. (...) A palavra é um constituinte da frase, efetua-Ihe a significação; mas não aparece necessariamente na frase com o sentido que tem como unidade autônoma. (BENVENISTE, 1966, p. 123-124)

Quando se diz que determinado elemento da língua (...) tem um sentido, entende-se aqui uma propriedade que esse elemento possui enquanto significante, de constituir uma unidade distintiva, opositiva, delimitada por outras unidades, e identificável pelos locutores nativos, de quem essa língua é $a$ língua. Esse "sentido" é implícito, inerente ao sistema linguístico e às suas partes. (BENVENISTE, 1966, p. 127-128)
\end{abstract}

A questão à qual voltamos ao término dessa seção é: qual "sentido" - para manter as aspas frequentemente empregadas por Benveniste ao falar em sentido - é este que uma unidade autônoma apresenta, sentido tido por "implícito, inerente ao sistema linguístico e às suas partes" (BENVENISTE, 1966, p. 127-128). Notemos ainda que é nesse mesmo artigo que Benveniste afirma que "o sentido de uma unidade linguística se define como sua capacidade de integrar uma unidade de nível superior" (BENVENISTE, 1966, p. 127), mostrando que as relações entre elementos de níveis diferentes são integrativas, diferentemente do que se observa entre elementos de um mesmo nível.

Esse tema retorna no artigo Sémiologie de la langue, no qual Benveniste apresenta dois modos distintos de significância: o semiótico, próprio ao signo, e o semântico, modo de significância engendrado pelo discurso. Ao tratar deste último modo, diz Benveniste que :

(...) a mensagem não se reduz a uma sucessão de unidades a ser identificadas separadamente; não é uma adição de signos que produz o sentido, é, ao contrário, o sentido (o "intentado"), concebido globalmente, que se realiza e se divide em "signos" particulares, que são as PALAVRAS. (BENVENISTE, 1974, p. 64)

(...) O semiótico (o signo) deve ser reconhecido; o semântico (o discurso) deve ser COMPREENDIDO. A diferença entre reconhecer e compreender remete a duas faculdades distintas do espírito: a de perceber a identidade entre o anterior e o atual, de um lado, e a de perceber a significação de uma significação nova, de outro. (BENVENISTE, 1974, p. 64-65)

A conclusão do artigo é bastante conhecida: o "mundo do signo é fechado", o que leva Benveniste a afirmar que "um hiato os separa", separa signo e palavra (frase). Também retomamos essa afirmação adiante.

Por fim, restam os excertos extraídos de La forme et le sens dans le langage, em maior número do que os dos outros artigos. A seleção tomou por base os excertos em que Benveniste faz considerações sobre o signo linguístico e sobre a palavra:

Em semiologia, o que o signo significa não é para ser definido. Para que um signo exista, é preciso e basta que seja aceito e que se vincule de um algum modo a outro signo. A entidade considerada significa? A resposta é sim ou não. Se é sim, tudo está dito e registre-se; se é não, é rejeitada e tudo está dito também. (...) Cada signo entra em uma rede de relações e oposições com outros signos que o definem, que o 
delimitam no interior da língua. Quem diz "semiótico" diz "intra-linguístico". Cada signo tem, no que lhe é próprio, o que o distingue de outros signos. (...) O signo tem sempre e somente valor genérico e conceitual. Ele não admite, portanto, significado particular ou ocasional; tudo o que é individual é excluído; (...) Se o inventário semiótico compreende o signo "se" (conjunção condicional), é preciso admitir também a sua função particular que é a função de indução, "se... então". Essa conclusão teria um interesse preciso, o fundamento da indução seria linguístico antes de ser lógico. (BENVENISTE, 1974, p. 222-223)

(...) o sentido da palavra é seu emprego (sempre na acepção semântica). (...) as palavras que estão dispostas em cadeia na frase e cujo sentido resulta precisamente da maneira pela qual são combinadas têm apenas empregos. O sentido de uma palavra consistirá na sua capacidade de ser integrante de um sintagma particular (...). O que se chama de polissemia nada mais é do que a soma institucionalizada, se se pode dizer, desses valores contextuais, sempre instantâneos, aptos circunstancialmente a se enriquecer, a desaparecer, em resumo, sem permanência, sem valor constante. (BENVENISTE, 1974, p. 226-227)

(...) cada palavra retém apenas uma pequena parte do valor que tem enquanto signo. (BENVENISTE, 1974, p. 229)

O conjunto de excertos selecionados e extraídos de quatro diferentes artigos - já que Nature du signe linguistique é propositalmente deixado para o término da seção - permite, no confronto com o que apresentamos na seção anterior, chegar a algumas conclusões sobre a natureza do significado ${ }^{4}$ do signo.

Retomemos, antes, algumas das considerações às quais chegamos ao analisar os artigos em que Benveniste procura definir prae e pánthāt:

- no que se refere à preposição prae, o autor afirma existir uma certa figura que coordena seus sentidos (em uso); ao definir prae, apresenta uma definição de natureza mais abstrata - diríamos, da ordem de uma relação, posto que nela se observam, a nosso ver, variáveis - a partir da qual examina as condições de emprego ("condições estritas") da unidade; notar que o autor fala ainda em "condições postas para a significação geral", "condição enunciada";

- ao empregar "traços distintivos", percebemos que esses traços não são da ordem de categorias semânticas universais, não são traços de conteúdo dados a priori e que se manifestariam, sob outra roupagem, nos diferentes empregos. Eles encontram-se relacionados aos caracteres, termo que, por sua vez, remete à condição enunciada aos quais o emprego de uma dada unidade obedece. A nosso ver, observam-se muito mais "demandas para se enunciar" em termos contextuais;

- a busca por uma definição constante aparece em relação à variação intralíngua e interlíngua; essa definição é, muitas vezes, associada a um esquema (uma certa figura, um esquema sublógico, um esquema subjacente).

Já, nos artigos selecionados nessa seção, lê-se, por sua vez, que:

- o dado linguístico é um resultado: é preciso procurar-lhe a origem; é por uma definição

\footnotetext{
${ }^{4}$ Notemos que Benveniste emprega, como já apontamos, sentido, e, na grande maioria das vezes, entre aspas. Preferimos empregar o termo significado, em referência à significado/significante, ainda que, logo adiante, ele faça um único uso de significado para falar em significado particular ou ocasional.
} 
sempre mais estrita dos signos linguísticos que progrediremos em direção a uma classificação racional;

- a palavra (...) não aparece necessariamente na frase com o sentido que tem como unidade autônoma; Quando se diz que determinado elemento da língua (...) tem um sentido, entende-se aqui uma propriedade (...) de constituir uma unidade distintiva (...). Esse "sentido" é implícito, inerente ao sistema linguístico e às suas partes;

- não é uma adição de signos que produz o sentido (...); O semiótico (o signo) deve ser reconhecido; o semântico (o discurso) deve ser COMPREENDIDO; (...) O signo tem sempre e somente valor genérico e conceitual. Ele não admite, portanto, significado particular ou ocasional; tudo o que é individual é excluído;

- o que o signo significa não é para ser definido. (...) Cada signo entra em uma rede de relações e oposições com outros signos que o definem, que o delimitam no interior da língua. (...) O que se chama de polissemia nada mais é do que a soma institucionalizada, se se pode dizer, desses valores contextuais, sempre instantâneos, aptos circunstancialmente a se enriquecer, a desaparecer, em resumo, sem permanência, sem valor constante.

- (...) cada palavra retém apenas uma pequena parte do valor que tem enquanto signo.

Voltemo-nos ao propósito primeiro deste trabalho, que envolve, num primeiro momento, a compreensão da natureza da identidade semântica da unidade linguística. A leitura dos excertos acima, nos quais Benveniste faz uma série de afirmações sobre o significado do signo (significado este comumente tratado como "sentido"), quando apoiada nas considerações feitas nos artigos em que Benveniste se atém a analisar unidades do campo morfolexical, adquire uma outra espessura, posto que são delineados caminhos que trazem mais sustentação para que aprofundemos alguns dos posicionamentos do autor.

Como se vê, propor uma definição mais estrita do signo é o que se encontra no fundamento de muitas de suas análises, posto que o dado linguístico é um resultado. Se pensarmos no que decorre dessa primeira afirmação, pode-se dizer que, a cada vez que se analisa o emprego de uma unidade linguística, o sentido que adquire nesse emprego não é o que será levado em consideração para que se chegue a uma definição mais estrita do signo, ao significado do signo. Não é por menos que Benveniste afirma, aliás, que "a polissemia nada mais é do que a soma institucionalizada, se se pode dizer, desses valores contextuais, sempre instantâneos, aptos circunstancialmente a se enriquecer, a desaparecer, em resumo, sem permanência, sem valor constante" (BENVENISTE, 1974, p. 227). A polissemia é um resultado da integração do signo à unidade que lhe é superior, a frase, e, no domínio da frase, os valores adquiridos são mutáveis: estamos no domínio do particular e do ocasional.

Por outro lado, não olhar para os valores que os signos costumam adquirir quando empregados não significa que se deixa de lado a análise minuciosa desses mesmos empregos. É justamente o que faz Benveniste ao analisar prae: ele não busca o sentido que prae adquire em cada uso: ele deixa de lado esse sentido para buscar o que se encontra na sua origem, $a$ figura que coordena seus sentidos (em uso), as condições postas para a sua significação geral. 
O exame dos agenciamentos próprios a cada emprego é constitutivo de sua metodologia. Se o autor utiliza definição geral - ou ainda, valor genérico e conceitual - para falar do significado do signo, fica evidente para nós que não há a menor possibilidade de associar tal definição ou valor genérico e conceitual a um conteúdo particular de natureza mais geral, mais precisamente, a traços de conteúdo. Ao falar em condição enunciada, Benveniste aponta, como mostramos na primeira seção, para um conjunto de caracteres que são entendidos como condições para se enunciar. De um certo modo, a cada emprego analisado, Benveniste busca mostrar de que modo se respondeu, num dado emprego, a essas condições. Isso explicaria igualmente os motivos de Benveniste associar a definição geral a um esquema, a ser lido de modo flexível, posto que entraria em jogo um conjunto de variáveis.

E o caso de pánthāt não deixa de ser diferente, pois, ainda que pudéssemos pensar que, ao falar em transposição, Benveniste estaria lhe conferido um "conteúdo", vemos que, ao analisar as diferentes línguas, o que ele mostra é como a transposição se reconstrói ao fazer referência a elementos que, embora específicos a cada uma das línguas mencionadas, retomam, a cada vez, o que se encontra no cerne do transpor: a presença de elementos distintos vistos como contínuos.

Isso nos permite voltar aos motivos que levam Benveniste a fazer um conjunto de afirmações sobre o que, para nós, deve ser lido como o significado do signo. Diz ele: "esse "sentido" é implícito"; "não é uma adição de signos que produz o sentido (...)"; "o semiótico (o signo) deve ser reconhecido"; "o que o signo significa não é para ser definido"; ou, ainda, "cada palavra retém apenas uma pequena parte do valor que tem enquanto signo".

Não vemos como não ser diferente: nos usos que fazemos da língua, só nos deparamos com empregos. Como diz Benveniste, o que está para lá dos empregos, é um processo “inconsciente, difícil de ser atingido, mas essencial" (BENVENISTE, 1966, p. 117). A definição que o autor dá para prae o apresenta por meio de um conjunto de caracteres que não foram feitos para ser compreendidos no momento em que ocorre seu emprego. O que se compreende, é o valor que prae adquire quando enunciado - ou seja, a palavra prae -, valor que, por ser o resultado da integração de prae à frase, certamente vê as variáveis constitutivas de sua definição apreendidas sob uma ótica particular: a que a frase lhe confere. Nessa perspectiva, apenas reconhece-se o signo, atesta-se a sua existência, mas o que ele significa está implícito, é "inconsciente" 5 .

Em suma, se Benveniste se utiliza do termo traços distintivos para descrever o signo, são muitos os argumentos que mostram não se tratar de um traço de conteúdo, posicionamento que levaria a um sentido anterior ao pôr em uso da língua incompatível com o pensamento enunciativo do autor, que pede, justamente, que nos "libertemos das falsas evidências, das referências às categorias semânticas "universais" (...)" (BENVENISTE, 1966, p. 307). Por outro lado, a significação geral constitutiva do significado do signo, apresentada em termos de definição constante, esquema ou qualquer que seja o termo empregado para

\footnotetext{
${ }^{5}$ Uma analogia a ser feita envolve a matemática, já que somos capazes de reconhecer diferentes figuras geométricas sem saber como defini-las do ponto de vista das relações que as constituem.
} 
defini-lo, como já discutimos à época de nossa tese (ROMERO-LOPES, 2000), é o que o leva a deslocar o domínio da arbitrariedade do signo para o campo da referência. Há, portanto, no significado do signo, uma necessidade dada pela condição enunciada aos quais os usos devem responder que faz com que Benveniste afirme, na conclusão de seu artigo Nature du signe linguistique que:

Se a língua é outra coisa além de um conglomerado fortuito de noções erráticas e de sons emitidos ao acaso, é por haver justamente uma necessidade imanente à sua estrutura, como a toda estrutura. (BENVENISTE, 1966, p. 55)

Em conclusão à discussão até aqui conduzida, a afirmação de que um hiato separa o signo da palavra pode ser lida, ao menos, sob a ótica da natureza conferida ao significado do signo e ao sentido da palavra: eles não são da mesma ordem. Há, no entanto, outra possibilidade de leitura, que envolve a relação de integração e que não será desenvolvida neste momento, por fugir ao escopo do trabalho. Remetemos, nesse caso, à seção " $A$ significação vista por E. Benveniste", que consta de Romero-Lopes (2000).

Abordando, agora, a questão da categorização linguística, à qual vamos nos ater de modo bem pontual, no artigo a respeito de prae, vemos, primeiro, que o autor afirma, em nota (BENVENISTE, 1966, p. 132, nota 2) não distinguir na análise preposição de prevérbio. Do mesmo modo, refuta classificações que distinguem o prae causal do prae comparativo.

O que se pode dizer a respeito desse posicionamento é que a busca pela significação geral associada a um esquema sublógico não leva em consideração classes ou categorias já estabelecidas: o que se considera é a forma prae enquanto termo reconhecido.

No caso do artigo sobre a reconstrução, no exemplo por nós mencionado, trata-se de uma comparação em grande escala, com várias línguas nas quais não há identidade de forma e nem, a princípio, identidade em relação ao sentido. Há, no entanto, "uma unidade semântica da família que é inegável", que embora pareça não poder se definir com precisão, o faz ir além do que se observa na diversidade superficial dos empregos.

Ora, esse modo de se olhar para os dados reforça a natureza do significado tal como ela foi por nós apresentada. Podemos dizer que, ainda que se saiba que uma dada classe, como preposição ou prevérbio, para guardar os termos utilizados pelo autor, mobilizem agenciamentos diferentes, trata-se de olhar, na análise, para os agenciamentos que lhes são próprios a fim de reconstituir o esquema que os define. E se isso é possível, é pelo fato de não se considerarem os sentidos que lhes são atribuídos em cada emprego, que não forneceriam qualquer base de reconstituição ou reconstrução.

E encerramos essa seção com um excerto extraído, dessa vez, de Catégories de pensée et catégorie de langues, que não consta do rol de artigos mobilizados para esse trabalho, mas que, como o conjunto dos artigos que integram a obra Problèmes de linguistique générale, tem o que nos dizer sobre o tema: "Sem dúvida, não é fortuito que a epistemologia moderna não tente constituir uma tábua de categorias. É mais produtivo conceber o espírito como virtualidade que como quadro, como dinamismo que como estrutura" (BENVENISTE, 1966, p. 73). De certo modo, podemos dizer que Benveniste abre o caminho para que se pense o 
intralinguístico de forma dinâmica, o que permite ao semiótico, quando em uso, proliferar em termos de sentido.

\section{Diálogos enunciativos: Émile Benveniste e Antoine Culioli}

Há quase três décadas, iniciamos, à época de nosso Mestrado, a busca por esse diálogo, que resultou na seção "A pulsação enunciativa da língua. De Benveniste a Culioli", que consta de nossa tese (ROMERO-LOPES, 2000), e da qual, salvo considerações que gostaríamos de aprofundar, ainda hoje partilhamos. Esse diálogo foi retomado na mesa "Benveniste e Culioli: (des)encontros teóricos e metodológicos", no âmbito da IV Jornada de Estudos léxico-gramaticais enunciativos, promovida pela UFPI, em 2018. Nessa mesa, em que estivemos Valdir Flores (UFRGS) e eu, sustentei que os encontros entre os dois linguistas são muito mais significativos do que seus possíveis desencontros.

O diálogo se dá, de saída, na concepção de linguagem que ambos defendem. Com efeito, Benveniste, em La forme et le sens dans le langage (1974), admite ser a linguagem uma "atividade significante por excelência, a própria imagem do que pode ser a significação" (BENVENISTE, 1974, p. 218). E acrescenta: "Que a língua signifique, isso quer dizer que a significação não é algo que lhe é dado por acréscimo ou (...) que é conferido a uma outra atividade: é o seu próprio ser. Se ela não fosse assim, não seria nada" (BENVENISTE, 1974, p. 219). Já Culioli não só defende ser a linguagem a atividade significante da espécie humana, como diz o que decorre desse posicionamento: "a atividade de linguagem não consiste em veicular sentido, mas em produzir e reconhecer formas enquanto traços de operações" (CULIOLI, 1990, p. 26).

Nesse pequeno excerto extraído do tomo I de Pour une linguistique de l'énonciation (CULIOLI), a produção e o reconhecimento de formas fazem referência à produção e ao reconhecimento de enunciados, ou seja, ao fato de que o sentido se elabora ao se produzir e/ou reconhecer um enunciado, não existindo sentido prévio a essa atividade de produção ou reconhecimento 6 ou que dela seja distinto, tal como é dito por Benveniste.

É, portanto, a linguagem como atividade o objeto primordial da Teoria das Operações Predicativas e Enunciativas:

\footnotetext{
${ }^{6}$ Nele é dito também haver, nos enunciados, traços de operações, operação devendo ser entendida como "operações mentais às quais (...) não se tem acesso direto. O perigo é o de fazer então o que foi proscrito pelos linguistas, i.e. fazer um psicologismo, mas um certo psicologismo muito intuitivo, ou ainda, fazer um logicismo, o que consiste em se apoiar em um sistema já pronto - a lógica clássica dos predicados ou um outro sistema para lhe fazer corresponder o funcionamento das línguas, notadamente por meio do estabelecimento de isomorfismos que conduzem a pensar que há uma relação evidente entre os representantes metalinguísticos e o que se busca apreender através dos traços. Operação remete, portanto, às operações mentais, mas também às operações metalinguísticas construídas a partir das observações e não a partir de um sistema existente" (CULIOLI, In: DUCARD, 2014, p. 9). Embora não tenhamos como aprofundar essa questão por ser necessário uma explanação consistente deste quadro referencial, deve-se ter em mente que falar em operação não se relaciona a abordar a cognição sob a ótica, nem de um "psicologismo intuitivo", nem da lógica. A esse respeito, ver Romero (2019).
} 
(...) de um lado, estou dizendo que o objeto da linguística é a atividade de linguagem (...); de outro, que só temos como apreender essa atividade, a fim de estudar seu funcionamento, por meio de configurações específicas, agenciamentos em uma dada língua. A atividade de linguagem remete a uma atividade de produção e reconhecimento de formas; ora, essas formas não podem ser estudadas independentemente dos textos, e os textos não podem ser independentes das línguas. (CULIOLI, 1990, p. 14, grifos do autor)

Se para uma parte das teorias linguísticas contemporâneas, falar em enunciado, como mostra De Vogüé (2017), supõe acrescentar um estrato distinto aos estratos sintático-semânticos já estabelecidos e que regem a estrutura das proposições, o que une Benveniste e Culioli é que ambos buscam integrar no enunciado o próprio processo que o constitui. Não é possível sustentar, assim, um nível específico - o do enunciado - a ser considerado como distinto de outro nível, o da proposição fora da enunciação (DE VOGÜÉ, 2017, p. 118).

Trazida para o coração da língua, a significação vai condicioná-la, regular o seu emprego, e é tal dinâmica que leva Benveniste a afirmar que, entre o significado e o significante, a relação é de necessidade. Como vemos em Romero-Lopes:

(...) a condição necessária unindo um significado e um significante é, na verdade, uma consequência natural de uma concepção na qual a significação é tida como o próprio ser da língua. Sem ela, seria logicamente impossível escapar de uma representação imaterial do sentido, já que, em tais circunstâncias, ao significante caberiam significados autônomos, frutos da "não necessidade", da "não dependência" postulada entre eles (...). [O resultado seria] o confinamento, no próprio signo, de um sentido cuja origem se encontra fora das próprias formas materiais, e em extensão, o rompimento da união significante/significado tida por indissolúvel. (ROMERO-LOPES, 2000, p. 45)

Benveniste, por meio da referência a uma significação geral, igualmente apreendida em termos de definição constante, esquema sublógico, esquema subjacente e outras variantes não discutidas aqui, evidencia a existência de uma dinâmica entre a unidade linguística e seus contextos verbais. Daí a necessidade frequentemente assinalada de se ater aos empregos, aos agenciamentos da unidade. A variação semântica responde assim a condições, formalizadas, se podemos dizer assim, a partir da observação do que ocorre com uma dada unidade quando esta se enuncia. Essas condições resultam no sentido da palavra, este, particular, ocasional, dado que contempla o universo do discurso.

Culioli, por sua vez, fala em invariância, que, como explicamos em Romero (2019), consiste em um conjunto de relações (entre termos) que se mantêm estáveis sob diferentes transformações. Esse conceito é central para a Teoria das Operações Predicativas e Enunciativas. No que se refere especificamente às pesquisas sobre a identidade semântica das unidades morfolexicais (FRANCKEL, 2002, CAMUS; DE VOGÜÉ, 2004, FRANCKEL; PAILLARD, 2007, ASHINO; DE PENANROS, 2016; ROMERO, 2019, entre outros), a invariância sustenta o conceito de esquema (de ordem da linguagem, i.e. esquema operatório) responsável por organizar a variação semântica de uma dada unidade lexical independentemente dos valores semânticos que lhe são atribuídos (de sua polissemia) ou de seu papel em diferentes 
construções sintáticas.

Isso significa que a definição da identidade semântica de uma dada unidade se dá por meio de "uma escritura" na qual se observa um esquema dinâmico, posto que constituído por "diferentes parâmetros que ele mobiliza. É bem de parâmetros que se trata: de entidades a serem fixadas para que o valor (semântico) se construa; de entidades cuja escritura precisa e restringe a forma e as relações que as vinculam" (DE VOGÜÉ, 2011, p. 18).

Não cabe, nesse artigo, trazer exemplos específicos de como se definem tais esquemas e de como eles organizam a variação semântica de uma dada unidade linguística. Há muitos trabalhos destinados a isso, dentre os quais mencionamos, nos estudos sobre o português do Brasil, Rocha (2019), Romero e Kiihl (2019), Romero e Trauzzola (2014, 2016), Romero (2013), Vilela (2016), Vilela e Rocha (2018), Romero e Vilela (2020), entre outros.

Para fornecer uma ilustração mais geral, como se lê em Romero (2019):

(...) interessa a essas pesquisas mostrar, [por exemplo], que, por trás dos inúmeros empregos do verbo romper em português do Brasil (PB), que o aproximam semanticamente e localmente de quebrar em $A$ enxurrada rompeu o cano; de começar, em Rompeu a guerra do Paraguai; de acabar, em A amizade entre eles rompeu-se definitivamente, para mencionar apenas uma ínfima quantidade de seus usos e construções, há uma forma invariante, constitutiva de sua identidade, capaz de explicar não só sua especificidade enquanto unidade linguística distinta de outras e sua variação semântica, mas, ainda, seu emprego como auxiliar em Uma cigarra rompeu a cantar.

Do mesmo modo que a identidade de romper se manifesta sem que ela seja afetada por sua função de verbo principal ou auxiliar, no caso de uma unidade como por, o fato de ela poder compor relações intra ou interproposicionais ou introduzir diferentes funções sintáticas também não interfere na sua forma invariante, que deve, pelo contrário, dar conta dessa variação. Logo, interessa, na análise, explorar a unidade em si (o marcador), seja em seu papel de preposição em Olhe por ela ou Passamos por Porto Seguro, seja em seu papel de integrante de locução conjuntiva, como no exemplo Por mais simples que seja o gesto, ele tem a ver com o conjunto, ou de conjunção, como elemento presente na morfologia de por que/porque. Em outras palavras, a forma invariante constitutiva da identidade de por deve contribuir para que se entenda como o mecanismo enunciativo que lhe é próprio atua nesses diferentes empregos, independentemente da classificação recebida. Deve ainda contribuir para que se proponha um formato de descrição unitário no caso em que compõe sintagma preposicional adquirindo diferentes funções sintáticas (argumento, adjunto, predicativo, etc.). (ROMERO, 2019, p. 183-184)

Em nota relacionada a esse excerto, mencionamos que as unidades de uma língua são estudadas como unidades transcategoriais, i.e. fora de toda categorização a priori, como se observa, justamente, no caso da ilustração de POR, ou no fato de não se levar em consideração o papel do verbo como principal e auxiliar no estudo de ROMPER.

Vê-se, nesses interesses, que Culioli retoma a tese de Benveniste de que a variação semântica responde a condições que determinam o funcionamento enunciativo de uma dada unidade linguística, além de sustentar posicionamento idêntico sobre a categorização linguística.

Benveniste mostra, portanto, haver uma dinâmica que organiza o enunciar da unidade linguística, sustentando igualmente que se "os agenciamentos materiais (...) puderem ser 
progressivamente relacionados às figuras diversas de um mesmo jogo e explicados por um certo número de princípios definidos, teremos ganhado uma base para a classificação racional dos elementos, das formas, e finalmente dos conjuntos linguísticos" (BENVENISTE, 1966, p. 118, grifos nossos).

Esses princípios restaram, contudo, a nosso ver, a ser detalhados na obra do autor, e é a eles que se dedica Culioli quando busca formalizar como se elaboram as representações linguísticas considerando-se que o nível linguístico (nível II, do enunciado) em que elas ocorrem não se apresenta como uma tradução do nível cognitivo (nível I, nocional, próprio à atividade de linguagem):

(...) o estudo dos textos mostra que não podemos nos ater a um jogo classificatório e hierárquico, em que representações fixas são encadeadas de modo linear. De que maneira conciliar a plasticidade das representações, dos ajustamentos intersubjetivos, a polissemia etc. e a necessária estabilidade de um sistema robusto, que deve ter as propriedades de todo sistema ao mesmo tempo fechado (daí o previsível) e aberto (daí os escalonamentos e deformações que comportam uma parte de imprevisível)? (CULIOLI, 1997, p. 13)

Deixamos ao leitor interessado nos estudos enunciativos, por meio da leitura dos tomos Pour une linguistique de l'énonciation (CULIOLI, 1990, 1999a, 1999b, 2018), dos artigos mencionados ou de tantos outros trabalhos destinados a diferentes línguas, ver como Culioli propõe a referida conciliação e quais são os princípios que se encontram no fundamento de seu referencial, princípios sob o quais se estabelece a atividade de linguagem.

O que podemos afirmar é que se tem, em Culioli, um modelo cuja clivagem subjetiva se encontra na própria gênese do enunciado, posto que entre o nível I, cognitivo, e o nível II, linguístico, verifica-se uma discordância irredutível, sem a qual não haveria nem plasticidade, nem ajustamentos. E esse é, sem dúvida, um achado teórico de primeira grandeza - e para nós, de uma beleza ímpar.

Benveniste, ao falar de Saussure no artigo Saussure après un demi-siècle, diz existir "em todo criador uma certa exigência, escondida, permanente, que o sustenta e o devora, que lhe guia os pensamentos, Ihe designa a sua tarefa, estimula-o nas suas fraquezas e não Ihe dá trégua quando, às vezes, ele tenta dela escapar" (BENVENISTE, 1966, p. 33).

Diríamos, em conclusão, que essa exigência, escondida, permanente, relacionada à compreensão do processo de significação, é o que une, de modo estrito, Émile Benveniste e Antoine Culioli em torno de um objetivo maior, que é o de compreender a natureza significante da linguagem, "patrimônio de todos os homens e [que] não cessa de despertar a [nossa] curiosidade" (BENVENISTE, 1966, p. 18).

\section{Referências}

ASHINO, F.; DE PENANROS, H. La préfixation verbale. Dossier thématique, Faits de Langues, Berne, n. 48, 2016. https://doi.org/10.1163/19589514-048-01-900000003

BENVENISTE, E. Problèmes de linguistique générale 1. Paris : Gallimard, 1966. 
BENVENISTE, E. Problèmes de linguistique générale 2. Paris : Gallimard, 1974.

CAMUS, R.; DE VOGÜÉ, S. (Dir.) Variation sémantique et syntaxique des unités lexicales : étude de six verbes français. LinX, Nanterre, n. 50, p. 7,13, 2004. https://doi.org/10.4000/linx.124

CULIOLI, A. Pour une linguistique de l'énonciation: opérations et représentations, Tome 1. Paris : Ophrys, 1990.

CULIOLI, A. A propos de la notion. In : RIVIÈRE, C. ; GROUSSIER, M.-L. (Dir.) La notion. Paris : Ophrys, 1997. p. 9-24.

CULIOLI, A. Pour une linguistique de l'énonciation : formalisation et opérations de repérage, Tome 2. Paris : Ophrys, 1999a.

CULIOLI, A. Pour une linguistique de l'énonciation : domaine notionnel, Tome 3. Paris : Ophrys, 1999b.

CULIOLI, A. Pour une linguistique de l'énonciation : tours et détours, Tome 4. Limoges: Lambert-Lucas, 2018.

DE VOGÜÉ, S. Os princípios organizadores da variedade das construções verbais. Tradução de Márcia Romero e Helena Valentim. ReVEL, Porto Alegre, v. 9, n. 16, p. 276-315, 2011.

DE VOGÜÉ, S. Effets sémantiques, syntaxiques et énonciatifs du jeu entre quantité et qualité. In : CAMUS, R., DE VOGÜÉ, S., MÉLIS, G. (Dir.) Variations sémantiques et syntaxiques. Aspects d'une théorie de l'invariance, LinX, Nanterre, v. 70-71, p. 141-163, 2014. https://doi.org/10.4000/linx.1575

DE VOGÜÉ, S. Quand la syntaxe est embarquée dans la construction discursive : l'énoncé chez Benveniste et chez Culioli. Langages, Paris, v. 1., n. 2015, p. 117-132. https://doi.org/10.3917/lang.205.0117

DUCARD, D. De l'énonciation à la " grammaire subjective " : entretien avec Antoine Culioli. In : DUCARD, D. Entre grammaire et sens : études sémiologiques et linguistiques. Paris: Ophrys, 2004. p. 7-20.

FRANCKEL, J.-J. (Dir.) Le lexique, entre identité et variation. Langue Française, Paris, n. 133, 2002. https://doi.org/10.3406/lfr.2002.1042

FRANCKEL, J.-J.; PAILLARD, D. Grammaire des prépositions. Paris : Ophrys, 2007.

ROMERO, M. Processos enunciativos e identidade semântica da preposição POR. Cadernos do IL, Porto Alegre, n. 46, p. 149-170, 2013. https://doi.org/10.22456/2236-6385.35642

ROMERO, M. Teoria das Operações Enunciativas. In: ROMERO, M.; GOLDNADEL, M.; RIBEIRO, P. N.; FLORES, V. N. Manual de Linguística: Semântica, Pragmática e Enunciação. Petropólis, RJ: Vozes, 2019. p. 175-228.

ROMERO, M.; KIIHL, J. P. Identidade e variação semânticas do verbo SECAR no português do Brasil. Estudos Linguísticos, v. 48, t. 3, 2019. https://doi.org/10.21165/el.v48i3.2259

ROMERO, M.; TRAUZZOLA, V. S. L. Identidade lexical, funcionamento enunciativo e variação semântica para a Teoria das Operações Enunciativas. Calidoscópio, v. 12, n. 2, p. 239-248, 2014. https://doi.org/10.4013/cld.2014.122.11

ROMERO, M.; TRAUZZOLA, V. S. L. Consumir et comer en portugais brésilien : contribution à l'étude du préfixe CO. Faits de Langues, Berne, n. 48, 2016. p. 79-92. 


\section{https://doi.org/10.1163/19589514-048-01-900000007}

ROMERO, M.; VILELA, T. R. Aspectos do papel enunciativo da preposição COM: objeto direto preposicionado e transitividade verbal. ReVEL, Porto Alegre, v. 18, n. 34, p. 152-183, 2020.

ROMERO-LOPES, M. C. Processos enunciativos de variação semântica e identidade lexical: a polissemia redimensionada. Estudo dos verbos jouer e changer. 2000, $333 \mathrm{f}$. Tese (Doutorado em Letras) - Programa de Pós-Graduação em Estudos Linguísticos, Literários e Tradutológicos em Francês. Universidade de São Paulo, 2000.

ROCHA, E. Operações de linguagem e o ensino de línguas: um estudo do marcador EM. 2019. 160 f. Tese (Doutorado em Ciências) - Programa de Pós-Graduação em Educação e Saúde na Infância e na Adolescência, Universidade Federal de São Paulo, Guarulhos, 2019.

VILELA, T. R. Educação léxico-gramatical: um estudo semântico-enunciativo da preposição COM. 2016, 190 f. Dissertação (Mestrado em Ciências) - Programa de Pós-Graduação em Educação e Saúde na Infância e na Adolescência, Universidade Federal de São Paulo, Guarulhos, 2016.

VILELA, T. R.; ROCHA, E. G. L. Um breve panorama: descrição e abordagem metodológica de preposições no português brasileiro. Estudos Linguísticos, São Paulo, v. 46, n. 1, p. 296-310, 2017. https://doi.org/10.21165/el.v46i1.1761

Recebido em: 04/12/2019. Aceito em: 09/03/2020. 